\title{
Predicting Flower Phenology and Viability of Highbush Blueberry
}

\author{
Anna K. Kirk ${ }^{\mathbf{1}}$ and Rufus Isaacs \\ Department of Entomology, 202 CIPS, 578 Wilson Road, Michigan State \\ University, East Lansing, MI 48824
}

Additional index words. Vaccinium corymbosum, base temperature, growing degree-day, bloom period

\begin{abstract}
To maximize yield of pollination-dependent agricultural crops, farmers must ensure that sufficient pollinators are present when flowers are open and viable. We characterized and compared the lower development threshold temperature, bloom phenology, and flower viability of five common cultivars of highbush blueberry (Vaccinium corymbosum $\mathrm{L}$.) to enable prediction of when flowers would be available for pollination. Threshold temperatures of all cultivars were found to be very similar and range between 7 and $8^{\circ} \mathrm{C}$. Logistic regression was used to characterize bloom phenology for all cultivars under field and greenhouse conditions. Bloom phenology under greenhouse conditions was delayed $\approx 100$ growing degree-days when compared with field conditions. Average flower viability was determined daily from first flower opening until 5 days after flower opening for each cultivar. Results indicated declining flower viability with increasing flower age with most flowers unsuitable for pollination more than 4 days after opening. Implications of these results for planning pollination of highbush blueberry fields are discussed.
\end{abstract}

A wide variety of variables, both genetic and environmental in origin, are known to influence plant growth and development. In agricultural systems, light intensity, air quality, soil nutrients, moisture, and air and soil temperature are particularly important environmental factors (Pessarakli, 2002). Monitoring environmental conditions can be crucial for farmers wishing to implement management practices at specific stages of crop development. For example, the phenological development of pollination-dependent agricultural crops is important to farmers seeking to maximize yield. Many farmers depend on rented honeybee hives for pollination (Delaplane and Mayer, 2000; James and Pitts-Singer, 2008). It is important for these managed pollinators to be introduced into agricultural crops only after flowering has begun to ensure pollination of the crop of interest as opposed to alternative foraging resources such as wildflowers (Free, 1993). The

Received for publication 7 May 2012. Accepted for publication 23 July 2012.

This research was funded by a MSU Plant Science Program Fellowship to A.K.K. and by the Michigan State University Rackham Foundation.

We thank Kyle Ringwald for excellent technical assistance. We also thank Jim Miller, Jim Hancock, Scott Swinton, and members of the Berry Crops Entomology laboratory at Michigan State University for reviewing earlier versions of the manuscript. Thanks to John Wise and the staff at Trevor Nichols Research Center for technical support and to the Southwest Michigan Research and Extension Center, MBG Marketing, Jawor Bros. Blueberries, Inc., DeGrandchamp Farms, and Cornerstone $\mathrm{Ag}$ LLC for access to their blueberry fields.

${ }^{1}$ To whom reprint requests should be addressed; e-mail kirkanna@msu.edu. ability to predict timing of crop flowering can improve placement of managed bee colonies near fields at the optimal time for pollination and also aid in maximizing crop yield.

Accurate prediction of biological events is fundamental to planting at an appropriate time, protecting crops from pests and inclement weather conditions, ensuring sufficient pollination, and planning the eventual harvest of crops (Bailey, 1947; Wielgolaski, 1999). The ability to predict important components of flower development such as flower opening and viability after anthesis would be useful for growers of crops dependent on insect-mediated pollination. If a crop requires cross-pollination, as is the case for many fruit crops (McGregor, 1976), it is also important to know the phenology of each participant cultivar to ensure that reproductively compatible varieties within the same area are in bloom at the same time. Finally, knowledge of the period of time during which flowers remain viable for pollination enables sufficient bee colonies to be purchased or rented to achieve the concentration of bees required for full crop pollination and yield potential.

For a large majority of fruit crop species, temperature and consequent heat accumulation are the most influential environmental factors that control development (Rathcke and Lacey, 1985; Schaffer and Anderson, 1994) and these are commonly monitored by farmers in early spring. One method of measuring heat accumulation incorporates both time and temperature into a unit called a growing degree-day (GDD), described in detail by Baskerville and Emin (1969). Because GDDs are calculated using a species-specific value for the critical lower threshold temperature below which plant development does not occur (base temperature), these heat units are universally functional and therefore allow bloom phenology to be predicted in many regions across a range of environments. The prediction of crop bloom based on GDD has been used in the past to predict bloom in almond [Prunus dultis (Mill) D.A. Webb] (DeGrandi-Hoffman et al., 1996; Rattigan and Hill, 1986), apple [Malus $\times$ sylvestris (L.) Mill. Var. domestica (Borkh.) Mansf.] (Anstey, 1966; DeGrandi-Hoffman et al., 1987), tomato [Lycopersicon esculentum Mill.] (Zalom and Wilson, 1999), apricot (Prunus armeniaca L.), cherry (Prunus avium L.), peach [Prunus persica (L.) Batsch], pear (Pyrus communis L.) (Anstey, 1966), and sunflower (Helianthus anuus L.) (Goyne et al., 1977), but this has not been accomplished for highbush blueberry [Vaccinium corymbosum (L.)]

Similarly, few studies have focused on the duration of flower viability in modern blueberry cultivars. An early study of 'Rubel' suggested that viability is greatest 1 to $2 \mathrm{~d}$ after flower opening (Merrill, 1936); however, this cultivar has been planted less frequently in recent years. In 1964, Moore documented that 'Bluecrop' flowers were receptive to pollen up to $5 \mathrm{~d}$ after flower opening under greenhouse conditions, whereas fruit set and seed number both decreased if the flower was pollinated more than $4 \mathrm{~d}$ after opening. Moore (1964) also investigated flower viability under field conditions for 'Coville' and 'Blueray'. His results indicate significant differences in flower viability for these cultivars, with flowers of 'Blueray' receptive to pollination for a longer period of time than those of 'Coville'. Rabbiteye blueberry (Vaccinium virgatum Ait. syn. $V$. ashei Reade) flowers are viable up to $5 \mathrm{~d}$ after anthesis (Brevis and NeSmith, 2006).

Additional data for highbush blueberry phenology and flower viability can be incorporated into mathematical models that predict bloom dependent on accumulated GDDs. Such decision support tools would provide highbush blueberry growers with a means to predict the dynamics of flower opening and flower viability using forecasted weather conditions. It would also allow for pollination strategies and management practices to be adapted depending on the projected length of blueberry bloom.

This study characterized and compared the bloom phenology of five common cultivars of highbush blueberry with respect to temperature accumulation. This was accomplished by first measuring bloom phenology as a function of temperature so that a lower threshold base temperature could be determined. Base temperatures were then used to calculate accumulated GDDs and relate that temperature accumulation to the bloom phenology of bushes grown under greenhouse and field conditions. In addition, flower viability was examined in each of the five cultivars under greenhouse and field conditions to determine the relationship between flower age and viability within and among cultivars. 


\section{Materials and Methods}

Highbush blueberry plants. Five commonly planted cultivars of northern highbush blueberry, $V$. corymbosum, were chosen to represent a range of early to late harvest periods. The cultivars used for all experiments were Duke, Bluecrop, Jersey, Elliott, and Liberty. Base temperature, phenology, and flower viability experiments were conducted in growth chambers in 2010-11, under greenhouse conditions in 2009 and 2011 and in Michigan highbush blueberry fields in 2009-11, respectively. Bushes used for growth chamber and greenhouse experiments were purchased from a local nursery in midwinter of each year. All plants were $\approx 2$ years old, in $3.8-\mathrm{L}$ pots, and remained in cold storage $\left(1\right.$ to $\left.2{ }^{\circ} \mathrm{C}\right)$ until removed for experimentation. In growth chamber experiments, plants were maintained at a 16:8 light to dark photoperiod. Mature bushes used for field experiments were selected within commercial fields that received similar levels of maintenance and were all located in the main blueberry production region of southwest Michigan, in Ottawa, Allegan, Van Buren, and Berrien Counties.

Base temperature of five highbush blueberry cultivars. Five sets of five plants, one from each cultivar, were removed from cold storage and one set was placed in each of five growth chambers set at constant temperatures of either $13,17,20,23$, or $26{ }^{\circ} \mathrm{C}$. Temperatures were chosen to span the range typically encountered during the period of blueberry bloom in the main regions where this crop is grown. The position of bushes was randomized in each chamber and light levels were recorded once a week using a field scout quantum meter (Spectrum Technologies, Inc., Plainfield, IL) to ensure consistency. Plants were allowed to progress from dormancy through flower bloom. Newly opened flowers were counted every 1 to $2 \mathrm{~d}$ and marked with a permanent marker to avoid duplicate counts. Each progression through bloom constituted one replicate, and three to five replicates were conducted for each cultivar/temperature pairing. Only three replicates were completed for the lowest temperature $\left(13{ }^{\circ} \mathrm{C}\right)$ as the bloom period was significantly extended.

Development rate was calculated as the inverse of the time elapsed between the start of bloom and $50 \%$ total bloom. Results were then plotted as temperature vs. development rate for each of five replicates. A one-way analysis of covariance compared the relationship of temperature and development rate for complete replicates (those including at least four temperature $\times$ development rate pairings) among the cultivars (PROC GLM; SAS Institute Inc., Cary, NC) using the development rate as the independent variable. The dependent variable was the temperature and the covariate was the experimental replicate. For each of the five cultivars, base temperature was calculated as the $\mathrm{x}$-intercept of the best fit regression line.

Highbush blueberry bloom phenology under greenhouse conditions. Ten potted highbush blueberry plants of each of the five cultivars were maintained at greenhouse temperatures of $15 \pm 5^{\circ} \mathrm{C}$. Temperature data were recorded using two $\mathrm{HOBO}^{\circledR}$ pendant temperature loggers (Onset Corporation, Bourne, MA) suspended at plant height in the greenhouse. To account for differences in base temperature among cultivars, air temperature data and individual cultivar base temperatures determined in the experiment described above were used to calculate accumulated GDD values. Accumulated GDD was measured from the time plants were removed from cold storage and placed in the greenhouse. Numbers of newly opened flowers were counted daily on each bush and marked with a permanent marker to avoid duplicate counts.

Highbush blueberry bloom phenology under field conditions. To observe highbush blueberry bloom under field conditions, three separate blueberry plantings in southwest Michigan were sampled during the 2009 and 2010 field seasons. Sites were chosen based on the availability of the five cultivars of interest being planted in close proximity. In 2009, the three sites sampled were located at the Southwest Michigan Research and Extension Center in Benton Harbor, the Michigan Blueberry Growers Association (MBG) headquarters in Grand Junction, and the Trevor Nichols Research Complex in Fennville. In 2010, the three sites sampled were located at the MBG headquarters in Grand Junction, Cornerstone Ag. in Lacota, and DeGrandchamp Farms in South Haven. Each site was equipped with a $\mathrm{HOBO}^{\circledR}$ Weather Station (Onset Corporation) that monitored on-site temperature conditions $1.5 \mathrm{~m}$ aboveground level.

To determine the progression of flower bloom as a function of temperature, bushes from each of the five cultivars were monitored for flower opening throughout the period of bloom while simultaneously collecting air temperature data at the three individual sites. At each site, 12 flower clusters in each of three plots per cultivar were flagged and monitored for flower opening (a total of 36 clusters per cultivar). For each plot, four flower clusters were flagged near the apical tip of a shoot, another four were flagged along the middle of a shoot, and the final four were flagged near the base of a shoot. Newly opened flowers from selected clusters were counted two to three times a week and marked with a permanent marker to keep track of which flowers had opened recently. Flagged flower clusters were observed throughout the entire period of bloom. Again, individual cultivar base temperatures determined previously were used to calculate accumulated GDD values, beginning on 1 Jan. of each year.

For all bloom phenology experiments, the relationship between percent total bloom and accumulated GDD for each cultivar was first analyzed using linear regression. No significant linear relationships were identified for either the original or transformed data taken from the greenhouse or field. The data were then plotted as percent total bloom vs. accumulated GDD for each cultivar to distinguish possible non-linear relationships.
Gaussian, gamma, and logistic nonlinear regression analyses were performed and parameters were compared among these non-linear curve types (PROC NLIN; SAS Institute Inc.). Although variations of each of these regressions fit the majority of phenology curves, only the logistic function was able to describe the relationships between percent total bloom (\%TB) and accumulated GDDs for each of the 15 individual curves. The PROC NLIN function was used to fit the following general logistic function to each curve:

$$
=\left[\frac{a+4 b^{*} \exp \left(-\left(\frac{G D D-p}{v}\right)\right)}{\left(1+\exp \left(-\left(\frac{G D D-p}{v}\right)\right)\right)^{2}}\right]
$$

In this equation, parameter $a$ is a measure of both the amplitude and variance of each logistic curve, whereas parameter $b$ describes the amplitude of the curve. Most importantly, the parameter $p$ represents an estimate of the number of accumulated GDDs where peak percent total bloom occurs and the parameter $v$ is an estimated value representative of the variance of each logistic bloom phenology curve. Parameters $a, b, p$, and $v$ were then compared among cultivars for each experimental setting using the estimated $95 \%$ confidence intervals provided by the PROC NLIN procedure to determine significant differences among the phenology curves of the cultivars. Only when the $95 \%$ confidence intervals had no overlap between cultivars were those cultivars determined to differ significantly for that particular bloom phenology characteristic.

Highbush blueberry flower viability under greenhouse conditions. To examine the relationship between flower age when pollinated and the resulting fruit set for individual flowers, 10 bushes of each of the five cultivars were maintained at greenhouse temperatures of $15 \pm 5^{\circ} \mathrm{C}$. To begin, all open flowers were removed from each bush. Each day, newly opened flowers for each cultivar were counted and assigned into groups of five. Groups of newly opened flowers were bagged with pollinator-exclusion mesh, which remained in place throughout the experiment, being removed only for hand pollination. Each group of five flowers constituted one replicate, and flowers were individually labeled using a hang tag with the replicate number (1-10), treatment (number of days to be allowed until pollination), date of opening, and date of pollination for ease of identification. For each of the 10 replicates per cultivar, one healthy flower was hand-pollinated at each of $0,1,2,3$, and $5 \mathrm{~d}$ after flower opening. Hand pollination was achieved by removing the corolla from the flower to be pollinated and depositing pollen from the same cultivar on the stigma of the flower with a small paintbrush. The pollen used for this hand pollination was collected by using a tuning fork to sonicate flowers and release pollen from additional potted bushes of the each of the cultivars (Buchmann and Hurley, 
1978). After pollination, flowers were monitored until berries ripened or the receptacle dried out to record presence or absence of fruit set.

Highbush blueberry flower viability under field conditions. Flower viability was examined under field conditions in the summer of 2011 for each of the five cultivars. Beginning before the start of flower bloom, one cane on each of 10 bushes per cultivar was bagged with pollinator-exclusion mesh and then monitored daily for flower opening. The pollinator-exclusion mesh remained on each cane throughout the experiment and was only removed for counting and hand pollination of flowers. Newly opened flowers were counted daily and assigned into 10 replicate groups of six flowers. Each group of six flowers constituted one replicate and flowers were individually labeled with a hang tag that described the replicate number (1-10), treatment (number of days allowed before pollination), date of opening, and date pollinated. For each of the 10 replicates per cultivar, one healthy flower was hand-pollinated at each of $0,1,2,3,4$, and $5 \mathrm{~d}$ after flower opening. Hand pollination was achieved in the same manner as the greenhouse flower viability experiments using pollen collected from bushes of the same cultivar in the same field. After pollination, flowers remained under pollinator-exclusion mesh and were monitored until berries ripened or the receptacle dried out to record presence or absence of fruit, and percent fruit set was calculated for each cultivar $X$ day combination.

For all flower viability experiments, percent fruit set values were compared using a two-way analysis of variance with cultivar and pollination treatment (time allowed between flower opening and hand pollination) as the main factors (PROC GLM; SAS Institute Inc.). Comparisons of pollination treatments were performed using Tukey's mean separation test at $P=0.05$.

\section{Results}

Base temperature of highbush blueberry cultivars. There were no significant differences among complete replicates within cultivars in the predicted base temperatures ('Bluecrop' $\mathrm{F}_{2,14}=0.23, P=0.80$; 'Duke' $\mathrm{F}_{2,12}=4.06, P=0.07$; 'Elliott' $\mathrm{F}_{2,9}=0.90, P=0.47$; 'Jersey' $\mathrm{F}_{2,14}=1.81$, $P=0.22$; 'Liberty' $\mathrm{F}_{2,8}=0.23, P=0.63$ ), so simple linear regression of all data points was performed for each cultivar. There were significant positive correlations between temperature and development rate for each cultivar $(P<0.0001)$ with $r^{2}$ values ranging from 0.623 for 'Jersey' to 0.806 for 'Elliott'. Base temperatures calculated as the $\mathrm{x}$-intercept of the best fit regression lines for the five cultivars ranged from $7.14{ }^{\circ} \mathrm{C}$ for 'Duke' to $7.96{ }^{\circ} \mathrm{C}$ for 'Liberty' (Table 1). These base temperature values were used to calculate cultivar-specific accumulated GDDs for subsequent analyses.
Highbush blueberry bloom phenology. Bloom phenology curves were calculated with respect to accumulated GDDs for each of the five cultivars using the previously determined base temperatures. In the greenhouse phenology experiments, the peak of bloom varied significantly among cultivars. Bushes of 'Duke' exhibited the earliest peak percent bloom $(p)$ followed by 'Bluecrop' and then 'Liberty', 'Elliott' and 'Jersey', which were not significantly different from one another (Table 2). Differences in peak percent bloom among cultivars were less apparent under field conditions in 2009 and 2010, but the order of peak percent bloom by cultivar was noticeably different from that observed under greenhouse conditions. Under field conditions, 'Liberty' exhibited the earliest peak percent bloom followed by 'Bluecrop', 'Duke', 'Jersey', and 'Elliott'. Parameter values for phenology curve variance $(v)$ were consistent among most cultivars in both field seasons with the exception of 'Jersey', which exhibited high inter- and intrayear variability. Parameters $a$ and $b$ were highly consistent with slight differences among cultivars appearing only for parameter $b$ under greenhouse conditions.

In general, highbush blueberry bloom occurred at much lower levels of accumulated GDDs under field conditions when compared with bloom phenology observed under greenhouse conditions. Analysis of all cultivars revealed that peak percent bloom occurred at 291 accumulated GDDs under field conditions compared with 420 accumulated GDDs under greenhouse conditions. Bloom phenology for each cultivar was consistent for the parameters $p$ and $v$ between the 2009 and 2010 field seasons and showed few differences for parameters $a$ and $b$ (Table 2).

Table 2. Parameter estimates and $95 \%$ confidence intervals for the best fit logistic phenology curves for five highbush blueberry cultivars measured under greenhouse and field conditions. ${ }^{z}$

\begin{tabular}{llccc}
\hline & \multicolumn{4}{c}{ Logistic curve parameter } \\
\cline { 2 - 5 } Cultivar & \multicolumn{1}{c}{$\mathrm{p}^{\mathrm{y}}$} & $\mathrm{a}^{\mathrm{w}}$ & $\mathrm{b}^{\mathrm{v}}$ \\
\hline & & Greenhouse & \\
Duke & $386 \pm 7 \mathrm{a}$ & $28 \pm 5 \mathrm{a}$ & $0.009 \pm 0.010 \mathrm{a}$ & $0.130 \pm 0.016 \mathrm{bc}$ \\
Bluecrop & $409 \pm 21 \mathrm{a}$ & $56 \pm 19 \mathrm{~b}$ & $0.005 \pm 0.018 \mathrm{a}$ & $0.079 \pm 0.013 \mathrm{ab}$ \\
Liberty & $444 \pm 15 \mathrm{~b}$ & $49 \pm 12 \mathrm{~b}$ & $0.002 \pm 0.015 \mathrm{a}$ & $0.074 \pm 0.009 \mathrm{ab}$ \\
Elliott & $447 \pm 9 \mathrm{~b}$ & $60 \pm 8 \mathrm{~b}$ & $-0.002 \pm 0.007 \mathrm{a}$ & $0.067 \pm 0.004 \mathrm{a}$ \\
Jersey & $465 \pm 30 \mathrm{~b}$ & $44 \pm 26 \mathrm{ab}$ & $0.008 \pm 0.041 \mathrm{a}$ & $0.103 \pm 0.025 \mathrm{~b}$ \\
& & & & \\
Duke & & Field 2009 & & $0.176 \pm 0.101 \mathrm{a}$ \\
Bluecrop & $275 \pm 24 \mathrm{a}$ & $21 \pm 16 \mathrm{~b}$ & $0.083 \pm 0.048 \mathrm{a}$ & $0.181 \pm 0.080 \mathrm{a}$ \\
Liberty & $240 \pm 103 \mathrm{a}$ & $-31 \pm 33 \mathrm{a}$ & $-0.313 \pm 2.157 \mathrm{a}$ & $0.251 \pm 0.331 \mathrm{a}$ \\
Elliott & $313 \pm 14 \mathrm{a}$ & $22 \pm 9 \mathrm{~b}$ & $0.031 \pm 0.063 \mathrm{a}$ & $0.280 \pm 0.094 \mathrm{a}$ \\
Jersey & $292 \pm 17 \mathrm{a}$ & $17 \pm 10 \mathrm{~b}$ & $0.044 \pm 0.093 \mathrm{a}$ & $0.327 \pm 0.161 \mathrm{a}$ \\
& & & & \\
Duke & & Field 2010 & & $0.205 \pm 0.096 \mathrm{a}$ \\
Bluecrop & $280 \pm 16 \mathrm{a}$ & $19 \pm 12 \mathrm{~b}$ & $0.029 \pm 0.069 \mathrm{a}$ & $0.175 \pm 0.059 \mathrm{a}$ \\
Liberty & $263 \pm 62 \mathrm{a}$ & $25 \pm 14 \mathrm{~b}$ & $0.024 \pm 0.065 \mathrm{a}$ & $0.170 \pm 0.080 \mathrm{a}$ \\
Elliott & $349 \pm 36 \mathrm{a}$ & $-45 \pm 36 \mathrm{a}$ & $-0.131 \pm 0.453 \mathrm{a}$ & $0.196 \pm 0.072 \mathrm{a}$ \\
Jersey & $319 \pm 27 \mathrm{a}$ & $32 \pm 19 \mathrm{~b}$ & $0.001 \pm 0.112 \mathrm{a}$ & $0.223 \pm 0.088 \mathrm{a}$ \\
\hline
\end{tabular}

${ }^{\mathrm{z}}$ For each experiment, values within the same column are not significantly different from one another if followed by the same letter.

${ }^{y}$ Estimate of the number of accumulated growing degree-days at which peak percent total bloom occurs.

${ }^{\mathrm{x}}$ Estimate of logistic curve variance.

"Measure of logistic curve amplitude and variance.

${ }^{\vee}$ Measure of logistic curve amplitude.

Highbush blueberry flower viability. Under greenhouse conditions, fruit set for newly opened flowers was $80.0 \% \pm 8.9 \%$ for all cultivars, declining to $16.2 \% \pm 8.2 \%$ $5 \mathrm{~d}$ later. There was significant variation in fruit set among the different times allowed between flower opening to pollen deposition $\left(\mathrm{F}_{4,211}=17.92, P<0.0001\right)$ with pollination $5 \mathrm{~d}$ after flower opening resulting in significantly lower fruit set than the other four treatments (Fig. 1A). Under field conditions, fruit set was not found to differ among pollination treatments $\left(\mathrm{F}_{5,220}=1.31, P=\right.$ 0.26) (Fig. 1B).

'Jersey' had the highest fruit set under greenhouse conditions $(69.3 \% \pm 17.1 \%)$, whereas 'Bluecrop' had the lowest average fruit set of $51.3 \% \pm 13.7 \%$. Fruit set did not differ significantly among cultivars $\left(\mathrm{F}_{4,211}=\right.$ $P=0.19$ ) (Fig. 2A). Under field conditions, fruit set varied significantly among the five cultivars $\left(\mathrm{F}_{4,220}=13.34, P<\right.$ $0.0001)$ and ranged from $37.8 \% \pm 11.1 \%$ for 'Liberty' to $93.3 \% \pm 2.3 \%$ for 'Bluecrop' Fig. 2B). A significant interaction between cultivar and duration until pollen deposition was found in both the greenhouse experiment

Table 1. Simple linear regression equations and calculated base temperatures for five highbush blueberry cultivars where $\mathrm{x}$ represents temperature $\left({ }^{\circ} \mathrm{C}\right)$ and y represents development rate.

\begin{tabular}{lccl}
\hline Cultivar & $\begin{array}{c}\text { Base temp } \\
\left({ }^{\circ} \mathrm{C}\right)\end{array}$ & $r^{2}$ & Regression equation \\
\hline Duke & 7.14 & 0.77 & $\mathrm{y}=0.0028 \mathrm{x}-0.019$ \\
Bluecrop & 7.42 & 0.75 & $\mathrm{y}=0.0031 \mathrm{x}-0.023$ \\
Elliott & 7.52 & 0.81 & $\mathrm{y}=0.0027 \mathrm{x}-0.020$ \\
Jersey & 7.93 & 0.62 & $\mathrm{y}=0.0031 \mathrm{x}-0.025$ \\
Liberty & 7.96 & 0.76 & $\mathrm{y}=0.0028 \mathrm{x}-0.022$ \\
\hline
\end{tabular}


A

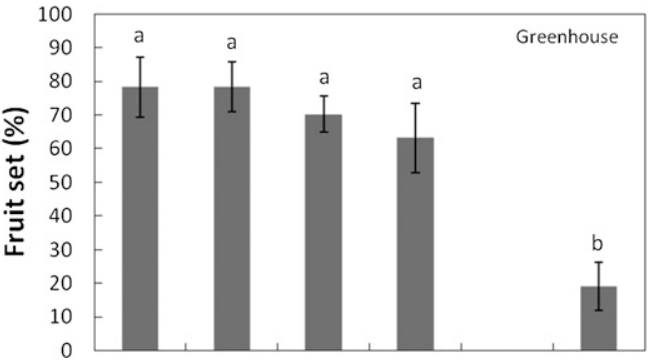

B

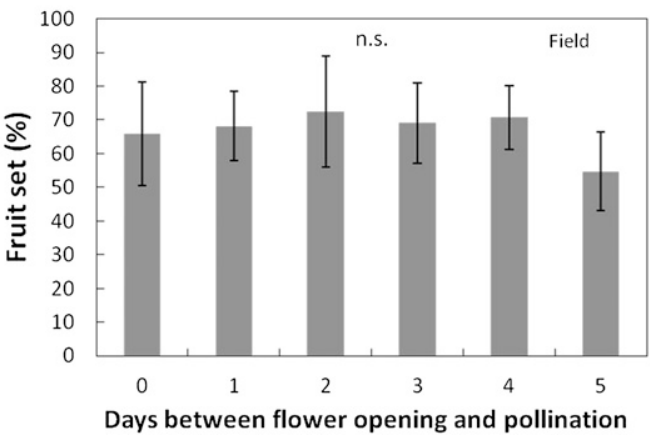

Fig. 1. Average fruit set of highbush blueberry when hand pollinated 0 to $5 \mathrm{~d}$ after flower opening under greenhouse (A) and field (B) conditions. Error bars represent SE. Hand pollination was not performed at $4 \mathrm{~d}$ after opening under greenhouse conditions.

A

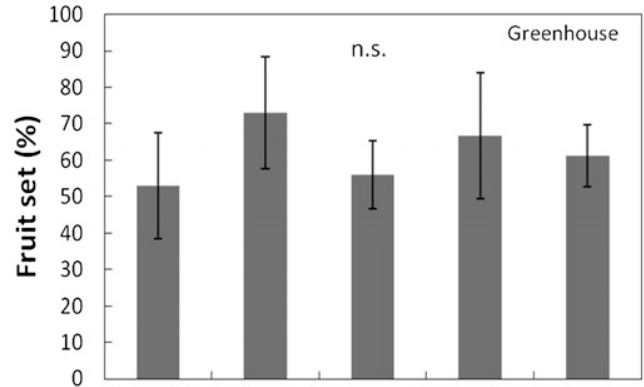

B

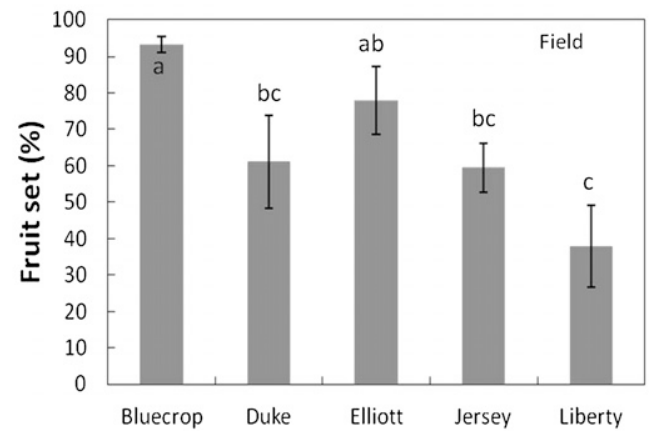

Fig. 2. Average fruit set for all treatments of five highbush blueberry cultivars under greenhouse (A) and field (B) conditions. Error bars represent SE.

$\left(\mathrm{F}_{16,211}=1.80, P=0.03\right)$ and field experiment $\left(\mathrm{F}_{20,220}=1.94, P=0.01\right)$.

\section{Discussion}

This study provides quantification of the bloom and flower aging phenology in highbush blueberry cultivars, revealing significant intercultivar differences that will support prediction of pollination in this crop. The relative values of bloom parameters determined here will also help managers plan their plantings of cultivars that require crosspollination by compatible cultivars. The results of this research show that for the five cultivars of highbush blueberry studied, base development temperatures fall between 7 and $8{ }^{\circ} \mathrm{C}$. These values reveal little variation in the base temperatures of five common highbush blueberry cultivars and suggest that it may be appropriate to assign the same range of base temperatures to all cultivars of highbush blueberry. Previous values used for the base temperature of highbush blueberry include $3{ }^{\circ} \mathrm{C}$ (Gough, 1994), $4.4{ }^{\circ} \mathrm{C}$ (Gough, 1983), $7.2^{\circ} \mathrm{C}$ (Darrow, 1942; Eck and Childers, 1966), and $10^{\circ} \mathrm{C}$ (Bryla et al., 2009). A study seeking to determine heat-unit models for predicting harvest of 13 highbush blueberry cultivars found that base temperatures of $-7,2,4$, or $7{ }^{\circ} \mathrm{C}$ could be used, depending on the cultivar (Carlson and Hancock, 1991). Our base temperature values determined here are relevant only to bloom prediction and should not be considered base temperatures for full-season development of highbush blueberry.

This study has also determined the relative bloom phenology based on GDD accumulation, of five highbush blueberry cultivars. It is commonly accepted that the highbush blueberry cultivars used in this study fall into a sequence of 'Duke', 'Bluecrop', 'Jersey', 'Liberty', and 'Elliott' when ordered according to the relative timings of berry harvest (Hancock, 2004; Hancock et al., 2001) There are no previously published data, however, on the comparative sequence of flower bloom in these cultivars; it has even been suggested that cultivar has no effect on the relative timing of blueberry bloom phenology (Eck, 1988). Our results suggest that highbush blueberry bloom phenology significantly differs according to cultivar and that it is predictable based on air temperature.

Bloom sequence under greenhouse conditions, as measured by accumulated GDDs at peak percent bloom, was found to follow a similar pattern as berry harvest: 'Duke', 'Bluecrop', 'Liberty', 'Elliott', and 'Jersey'. Because there was no significant difference in accumulated GDDs at peak percent bloom for 'Liberty', 'Elliott', and 'Jersey', these findings support the previously assumed order of highbush blueberry cultivar phenology and justify grower planting choices that are based on strategies of staggering the bloom periods of multiple cultivars in individual or adjacent fields. Such a strategy can help spread the demand for bees to pollinate fields at one time and enable more efficient pollination. Highbush blueberry is known to be parthenocarpic (Coville, 1910; Dogterom et al., 2000; Eck, 1988; Gough, 1994; MacKenzie, 1997) but the extent of parthenocarpy varies according to cultivar; therefore, overlapping compatible cultivars can also help ensure cross-pollination that would provide increased berry size (Luby et al., 1991; MacKenzie, 1997; McGregor, 1976; Meader and Darrow, 1947; Vander Kloet, 1982).

For all cultivars, peak percent bloom occurred at significantly lower accumulated GDDs under field conditions than in the greenhouse environment. These differences could be attributed to horticultural differences between potted blueberry plants and those under field conditions, receiving regular fertilization, tilling, etc. Bushes grown in the greenhouse also experienced different light quality (spectral wavelength distributions) than the natural sunlight received by field plants, another factor that may have contributed to the differences observed in 
bloom phenology (Smith, 1982). Also, the differences in age between potted bushes used for greenhouse experiments and the mature bushes under field settings could account for the differences in bloom phenology. Although many growers observe no difference in the blooming characteristics of young vs. mature blueberry plants (M. DeGrandchamp, personal communication), plant development over time is sometimes nonlinear and can change with age (Wang, 1960). Similarly, plant development with respect to environmental variables is also often a nonlinear relationship (Evans, 1972).

Possibly the most influential factor contributing to the differences observed in greenhouse and field phenology is the amount of chilling hours experienced. NeSmith and Bridges (1992) examined the relationship between accumulated chilling hours and rabbiteye blueberry bloom phenology and found an increased rate of bloom development with increased chilling hours. Assuming a similar relationship between chilling hours and development for highbush blueberry, this difference would account for the observed shift in bloom for greenhouse plants where bloom was delayed by $\approx 100$ GDDs. Although both field and greenhouse bushes in this experiment received the minimum recommended amount of chilling hours, 600 1000 chilling hours (Pritts and Hancock, 1992), the bushes pulled out of cold storage and grown in the greenhouse received a lower number of chilling hours than those assessed in the field. The effect of this on bloom phenology means that greenhouse data provide relative, but not absolute, values for bloom timing in the cultivars tested.

We found that highbush blueberry flowers are most viable for fruit set when pollinated up to $4 \mathrm{~d}$ after flower opening. Greenhouse and field experiments yielded contrasting results, but this is to be expected because environmental and management conditions are different between the two. Field conditions involve variable air and soil temperatures, soil moisture and nutrients, pruning, fertilization, and other factors known to be important components of highbush blueberry development and fruit set (Goulart et al., 1997; Hall et al., 1963; Holzapfel et al., 2004; Strik and Buller, 2003), whereas greenhouse experimentation allows for consistent levels of many of these variables. The interaction between cultivar and duration until pollen deposition found in both greenhouse and field experiments can be considered to be the result of multiple blueberry cultivars responding differently to increasing intervals of time before pollination. Even taking into account these differences, greenhouse and field results indicate that the reduction in fruit set is most significant when increasing the amount of time elapsed between flower opening to pollination to $5 \mathrm{~d}$. In fact, at $5 \mathrm{~d}$ after anthesis, many floral stigmas either appeared unsuitable for pollination or had fallen off entirely. Previous studies on highbush blueberry flower viability have found flowers to remain viable up to 5 (Merrill, 1936) or $8 \mathrm{~d}$ after anthesis, although fruit set, berry weight, and seed number were found to decrease after $4 \mathrm{~d}$ (Moore, 1964). Interestingly, under greenhouse and field conditions, blueberry flowers appeared to show slightly increased viability when pollinated 1 to $2 \mathrm{~d}$ after opening rather than when pollinated on the day of opening. These results support those of Merrill (1936) who suggested that the optimum time of pollination is 24 to $48 \mathrm{~h}$ after flower opening.

Finally, the cultivar of highbush blueberry appeared to have no effect on flower viability in the greenhouse but was a significant variable affecting flower viability under field conditions. This difference appears to have been driven in part by the low fruit set values of the field-planted 'Liberty' that led to a significant variation among cultivars. These results may be explained to some extent by winter injury to young bushes. 'Liberty' was introduced into commercial highbush blueberry production relatively recently and its performance in the field has been variable in Michigan to date. Had these bushes been closer in maturity to those of the other more established cultivars, differences in fruit set values may have been less apparent.

Our results are important for the growers of highbush blueberry because they can use this knowledge of blueberry phenology to better schedule management practices relative to the timing of bloom and the placement of managed honeybee hives in the field between $5 \%$ and $25 \%$ bloom (Howell et al., 1972, Pritts and Hancock, 1992). When combined with other pollination guidelines such as observing four to eight honeybees per bush for optimum pollination (Pritts and Hancock, 1992), growers may be able to make more knowledgeable managed pollination decisions. It is important to further explore this optimization of managed pollination efforts as a response to potential pollinator declines that may threaten the productivity of pollination-dependent crops (Aizen et al., 2008).

\section{Literature Cited}

Aizen, M.A., L.A. Garibaldi, S.A. Cunningham, and A.M. Klein. 2008. Long-term global trends in crop yield and production reveal no current pollination shortage but increasing pollinator dependency. Curr. Biol. 18:1572-1575.

Anstey, T.H. 1966. Prediction of full bloom date for apple, pear, cherry, peach and apricot from air temperature data. Proc. Amer. Soc. Hort. Sci. 88:57-66.

Bailey, J.S. 1947. Development time from bloom to maturity in cultivated blueberries. Proc. Amer. Soc. Hort. Sci. 49:193-195.

Baskerville, G.L. and P. Emin. 1969. Rapid estimation of heat accumulation from maximum and minimum temperatures. Ecology 50:514517.

Brevis, P.A. and D.S NeSmith. 2006. Flower age affects fruit set and stigmatic receptivity in rabbiteye blueberry. HortScience 41:15371540.
Bryla, D.R., B. Yorgey, and A.D. Shireman. 2009. Irrigation management effects on yield and fruit quality of highbush blueberry. Acta Hort. 810:649-656.

Buchmann, S.L. and J.P. Hurley. 1978. A biophysical model for buzz pollination in angiosperms. J. Theor. Biol. 72:639-657.

Carlson, J.D. and J.F. Hancock, Jr. 1991. A methodology for determining suitable heat-unit requirements for harvest of highbush blueberry. J. Amer. Soc. Hort. Sci. 116:774-779.

Coville, F.V. 1910. Experiments in blueberry culture. U.S. Dept. Agr. Bul. 193.

Darrow, G.M. 1942. Rest period requirements of blueberries. Proc. Amer. Soc. Hort. Sci. 41: 189-194.

DeGrandi-Hoffman, G., R.A. Hoopingarner, and R. Pulcer. 1987. REDAPOL: Pollination and fruit set prediction model for 'Delicious' apples. Environ. Entomol. 16:309-318.

DeGrandi-Hoffman, G., R. Thorp, G. Loper, and D. Eisikowitch. 1996. Describing the progression of almond bloom using accumulated heat units. J. Appl. Ecol. 33:812-818.

Delaplane, K.S. and D.F. Mayer. 2000. Crop pollination by bees. CABI Publishing, New York, NY.

Dogterom, M.H., M.L. Winston, and A. Mukai. 2000. Effect of pollen load size and source (self, outcross) on seed and fruit production in highbush blueberry cv. 'Bluecrop' (Vaccinium corymbosum; Ericaceae). Amer. J. Bot. 87: 1584-1591.

Eck, P. 1988. Blueberry science. Rutgers Univ. Press, NJ.

Eck, P. and N.F. Childers. 1966. Blueberry culture. Quinn and Boden, NJ.

Evans, G.C. 1972. The quantitative analysis of plant growth. Blackwell Scientific Publications, Oxford, UK.

Free, J.B. 1993. Insect pollination of crops. Academic Press, Inc., San Diego, CA.

Gough, R.E. 1983. Time of pruning and bloom date in cultivated highbush blueberry. HortScience 18:934-935.

Gough, R.E. 1994. The highbush blueberry and its management. Food Products Press, New York, NY.

Goulart, B.L., K. Demchak, and W.Q. Yang. 1997. Effect of cultural practices on field grown 'Bluecrop' highbush blueberries, with emphasis on mycorrhizal infection levels. Acta Hort. 466:271-278.

Goyne, P.J., D.R. Woodruff, and J.D. Churchett. 1977. Prediction of flowering in sunflowers. Aust. J. Exp. Agr. Anim. Husb. 17: 475-481.

Hall, I.V., D.L. Craig, and L.E. Aalders. 1963. The effect of photoperiod on the growth and flowering of the highbush blueberry (Vaccinium corymbosum L.). Proc. Amer. Soc. Hort. Sci. $82: 260-263$

Hancock, J., E. Hanson, and D. Trinka. 2001. Blueberry varieties for Michigan. Ext. Bul. E-1456.

Hancock, J.F. 2004. Blueberry plant denominated Liberty. U.S. Plant Patent No. P115,146.

Holzapfel, E.A., R.F. Hepp, and M.A. Mariño. 2004. Effect of irrigation on fruit production in blueberry. Agr. Water Mgt. 67:173184.

Howell, G.S., M.W. Kilby, and J.W. Nelson. 1972. Influence of timing of hive introduction on production of highbush blueberries. HortScience 7:129-131.

James, R. and T.L. Pitts-Singer. 2008. Bee pollination in agricultural eco-systems. Oxford University Press, New York, NY. 
Luby, J.J., J.R. Ballington, A.D. Draper, K. Pliszka, and M.E. Austin. 1991. Blueberries and cranberries (Vaccinium). Acta Hort. 290:393458.

MacKenzie, K.E. 1997. Pollination requirements of three highbush blueberry (Vaccinium corymbosum L.) cultivars. J. Amer. Soc. Hort. Sci. 122:891-896.

McGregor, S.E. 1976. Insect pollination of cultivated crop plants. U.S. Dept. Agr., Agr. Res. Serv. Hdbk. 496.

Meader, E.M. and G.M. Darrow. 1947. Highbush blueberry pollination experiments. Proc. Amer. Soc. Hort. Sci. 49:196-204.

Merrill, T.A. 1936. Pollination of the highbush blueberry. Mich. Agr. Expt. Sta. Bul. 151.

Moore, J.N. 1964. Duration of receptivity to pollination of flowers of the highbush blueberry and the cultivated strawberry. Amer. Soc. Hort. Sci. 85:295-301.
NeSmith, D.S. and D.C. Bridges. 1992. Modeling chilling influence on cumulative flowering: A case study using 'Tifblue' rabbiteye blueberry. J. Amer. Soc. Hort. Sci. 117:698-702.

Pessarakli, M. 2002. Handbook of plant and crop physiology. Marcel Dekker, New York, NY.

Pritts, M.P. and J.F. Hancock (eds.). 1992. Highbush blueberry production guide. Northeast Reg. Agr. Eng. Serv. Publ. 55.

Rathcke, B. and E.P. Lacey. 1985. Phenological patterns of terrestrial plants. Annu. Rev. Ecol. Syst. 16:179-214.

Rattigan, K. and S.J. Hill. 1986. Relationship between temperature and flowering in almond. Aust. J. Exp. Agr. 26:399-404.

Schaffer, B. and P.C. Anderson (eds.). 1994. Handbook of environmental physiology of fruit crops. 2 Vols. CRC Press, Boca Raton, FL.
Smith, H. 1982. Light quality, photoperception, and plant strategy. Annu. Rev. Plant Physiol. 33:481-518.

Strik, B. and G. Buller. 2003. Pruning severity affects yield, berry weight and hand harvest efficiency of highbush blueberry. HortScience 38:196-199.

Vander Kloet, S.P. 1982. Effects of pollen donors on seed production, seed weight, germination and seedling vigor in Vaccinium corymbosum L. Amer. Midl. Nat. 112:392-396.

Wang, J.Y. 1960. A critique of the heat unit approach to plant response studies. Ecology 41:785-790.

Wielgolaski, F.E. 1999. Starting dates and basic temperatures in phenological observations of plants. Intl. J. Biometeorol. 42:158-168.

Zalom, F.G. and L.T. Wilson. 1999. Predicting phenological events of California processing tomatoes. Acta Hort. 487:41-48. 